\title{
A Study on the Lack Touch in English Literature Originals Based on Questionnaire
}

\author{
Aitian Zhang \\ College of Foreign Studies \\ Shandong Technology and Business University \\ Yantai, China
}

\author{
Dapeng Zhou \\ College of Foreign Studies \\ Shandong Technology and Business University \\ Yantai, China
}

\begin{abstract}
The influence of original English learning on college students should not be underestimated. In this paper, a questionnaire is conducted to investigate and analyze the original works of non - English majors in a university in Shandong province. The results show that students think the effective way to absorb the foreign language is reading English original works, and it is necessary to contact English literature originals, but there is still a gap between what they expect to achieve and what they can actually achieve. This paper argues that the current situation of teaching and learning English originals should be changed to make it more operational and feasible. It is hoped that this paper can provide some constructive advices on the touch and learning of English originals for teachers and students.
\end{abstract}

Keywords—questionnaire survey; English literature originals; lack touch; proposals

\section{INTRODUCTION}

Literature masterpieces usually mirror the culture of a country or area in a specific period of time. By reading these masterpieces, we can enjoy the authors' fluent writing styles, vivid and full of colors description, which will place us in that specific period's history and culture. Therefore reading literature masterpieces, especially original masterpieces, has always been very important to English-learning students. Students can learn how to write and speak the English language because cultural character traits, themes, ideas and values are revealed in imaginative literature, importantly, students can understand the context and meaning of famous quotes and phrases. It would be very helpful to develop the right sense of English language.

\section{INVESTIGATION MotiVE}

To plenty of non-English majors in Chinese universities, English has always been giving top priority in pursuing a higher education and career. A high command of English has become a magic weapon to the ideal path. But up to now still many students who have put money and energy have not got obvious effects.

In the eyes of the writer, while learning English if we don't touch English literature originals, we could not draw ideal nutrition from the essence of British and American literatures, could not completely appreciate the elegant styles of famous masters, let alone use English language skillfully.
Therefore, the lacking touch in English literature originals may cause many problems in English Learning: misunderstanding of culture, inaccurately use of language, bias views towards some events, hard to build up sense of language, and confusion of contextual application, etc. How to tackle these obstacles has aroused college students' attention. In order to make clear how the students attach importance to the English literature originals and the relationship between English literature originals with English learning, we conducted a questionnaire and made statistical analysis and research on it.

In the questionnaire survey, we found that most students ignore the original learning, the specific reasons are different, but the common one is that utilitarian motive is too strong. In order to achieve the immediate purposes to learn scattered language knowledge and ignore the load of language and culture of the classic originals, which is precisely beneficial to promote the learning of language knowledge. The purpose of this paper is to explore a phenomenon that Chinese college students often ignore reading time and reading volume of English original works in English learning, and to analyze the causes of this phenomenon and propose solutions. I hope to appeal to teachers and students to pay serious attention to the English literature originals learning, to really understand the culture and customs of the target language countries, so students can reach the ideal height in language.

\section{DESIGN QUESTIONNAIRE}

Survey object: This questionnaire was conducted in Agrade class of hierarchical teaching grade $A B$ of 2017 in a university in Shandong province, in the form of a network answer. 113 questionnaires were collected in real time. Students who participated in the questionnaire come from the first year of Law School, School of Public Administration, School of Computer Science and Technology, Economics School. Comparatively speaking, they scored better in the entrance examination for freshmen than in B-grade class. As a result, these students are expected to have higher expectations.

Questionnaire: The multiple-choice questions were designed in the questionnaire. Each multiple-choice question was designed with 4 - 6 options, and students could make multiple choices according to their own situation, 
understanding and ideas. The purposes of this questionnaire were to know the students' real views and attitudes towards the original English learning, to collect the first-hand information, so as to make effective analysis and research, and to give constructive suggestions on English literature original learning.

\section{FINDINGS AND ANALYSIS}

\section{A. The Question How Many Students Have Touched the Original English Learning}

When the 113 college students were asked when they started to learn English, as following "Fig. 1", 73.5\% students said they had learnt it since primary schools while 19.5 students even stated that they began to learn English since kindergarten. That means $93 \%$ students have learned
English for more than 12 years. But Regrettably, when asked how many English literature originals (ELOs) have been read entirely in 12 years, whether they could read an ELO yearly, most of them felt sorry, only a small number of students actually have read the original English literatures which they liked reading very much. As shown in "Fig. 2", in the long 12 years, as more as $61.1 \%$ students have touched only 1 3 English literature originals (ELOs); and 23\% just have read some excerpts, which some excerpts even were selected from the textbooks; only 1 student has read more than 10 ELOs. From the above data, we can see that the students are very lack of original reading, which seriously affected their hunting for English language and English culture. Strictly speaking, during 12 years 12 works are not too much for students on average. Therefore, good and practical methods to encourage students to read English literature originals (ELOs) are badly needed.

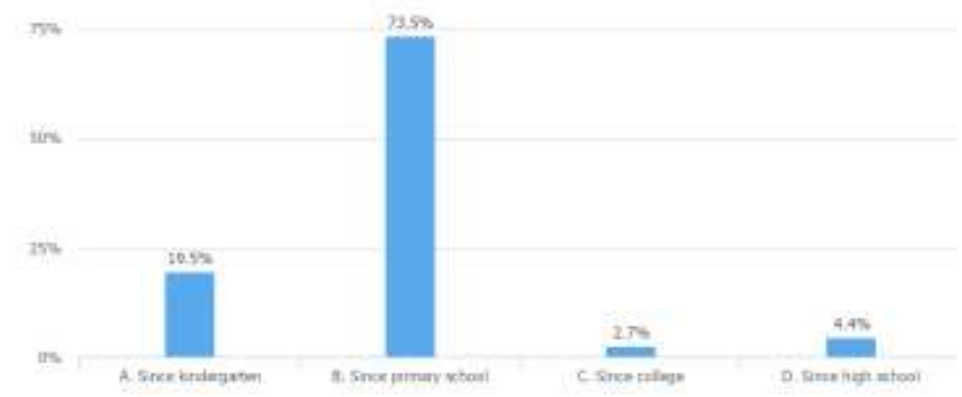

Fig. 1. The Question How many students have touched the original English learning?

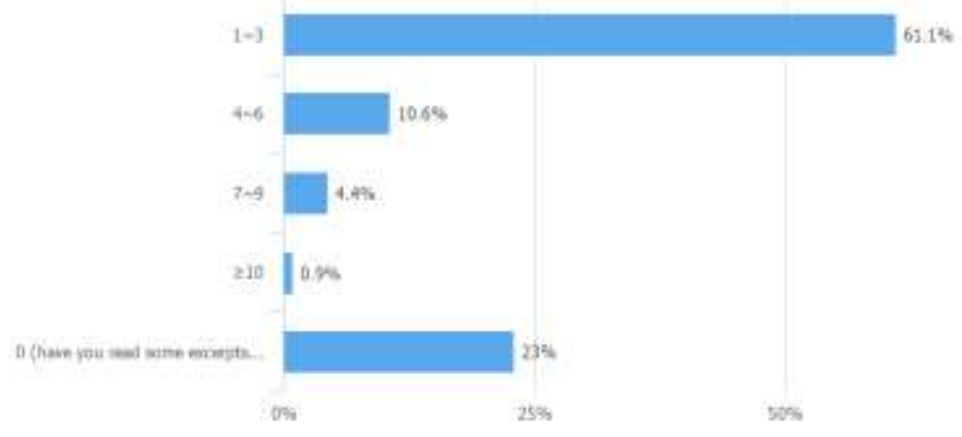

Fig. 2. How Many English literature originals hvee been read entirely?

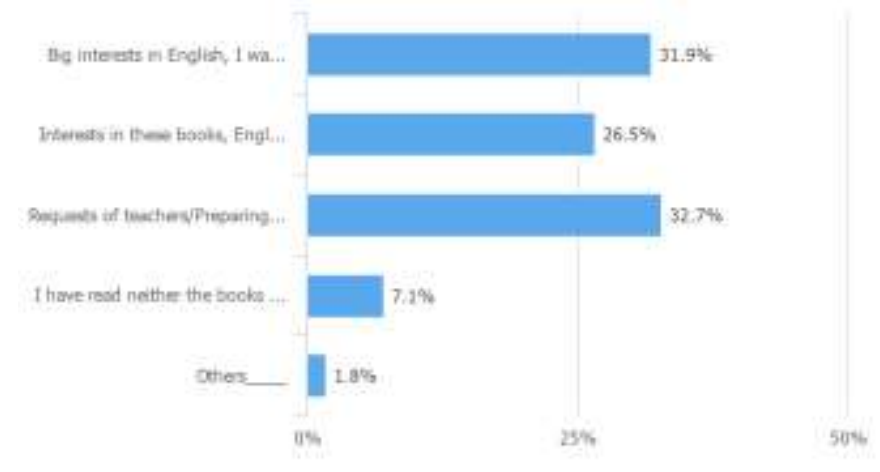

Fig. 3. The reason for you to read English literature originals (ELOs)? Mainly due to... 


\section{B. The Reason for Reading English Literature Originals (ELOs)? Mainly due to...}

According to "Fig. 3" above, nearly one third of the students read English literature originals in order to meet the immediate needs of their study ----"Preparing for future exams"; or "Requests of teachers". But at the same time, over half the students read English literature originals on their own initiative, regardless of different reasons (interests in English or in book itself). This result means that if we want to polish up students' English, we have to give preference to developing their interest in reading in English.

\section{The Question Do You Think You Read Enough English Literature Originals? If don't, Why don't You Read More often?}

"Fig. 5" next page shows that only $31 \%$ are satisfactory with their reading quantity of English literature originals (ELOs), while 69\% students think they are far from enough of English literature originals (ELOs) reading. Now that they have realized the English literature originals' reading is insufficient, why don't they strengthen and read more? As shown in the following figure.4, facing the question, a high proportion of students revealed the truth: $42.3 \%$ speak frankly and sincerely that "English literature originals scare me because they are difficult"; $34.6 \%$ students mentioned "I have no access to English literature originals which interest me so much" and $26.9 \%$ also express "I have no time to read". From the statistics, we can be sure if we teachers make a good guideline to students about how to deal with English literature originals (ELOs), students will be greatly encouraged to like reading and appreciating the beauty of ELO, instead of being scared before reading it. For example, rather than encouraging students to read literary classics like Shakespeare's dramas or Jane Eyre, we can recommend English literature originals (ELOs) much more modern and attractive for young people. All roads lead to Rome. If romances like Harry Potter, Twilight, even Fifty Shades of Grey in English interest students and give them strong desire to read, we teachers couldn't deny their charm, neither their constructive role in English teaching. Another method consists in introducing often to students popular Englishspeaking authors at present such as Stephen King, Harlan Coben, reading trend such as crime novels and the bestsellers in western countries in order to make recommended ELO more attractive as well as fashionable. The best thing to study English is to connect with the native English-speaking world.

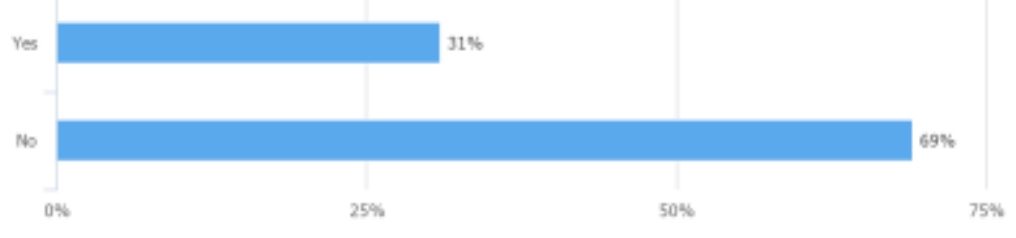

Fig. 4. If don't, why don't you read more often?

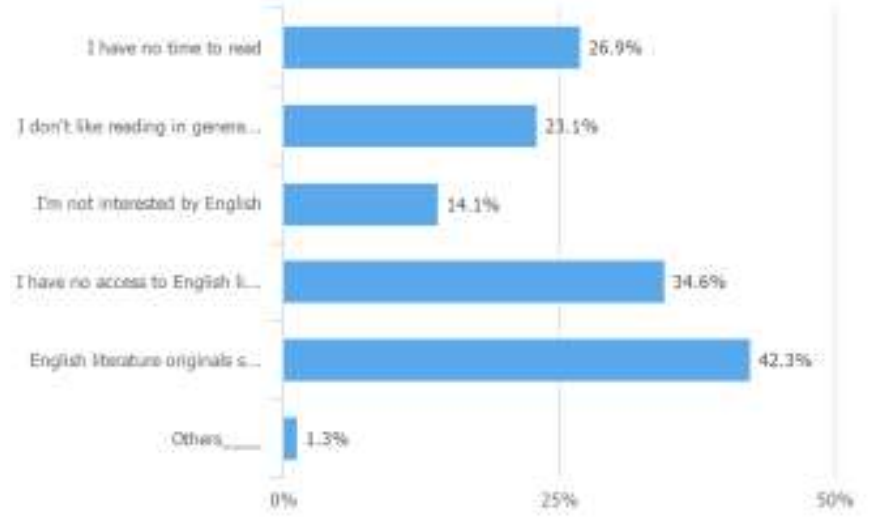

Fig. 5. Do you think you read enough English literature originals?

\section{The Question What Problems Have You Encountered most often When Reading Them? How do you Handle Most often this Problem}

Even if they have overcome the obstacles of psychological barriers of fear to try to read, they often meet many challenges while reading. As following "Fig. 6", among these, the considerable percentages are $39.8 \%$ students "Don't understand the sentence structure" and $31 \%$
"Don't understand the words" respectively, which show that the students have weak foundation in English even they have learned English for over ten years. Another part of students, $20.4 \%$, who could basically finish reading ELO, also face a big problem like this "Understand but can't feel the beauty of the original texts". To solve these problems, and at the same time, not to hurt students' enthusiasm for learning English original works, teachers should make long-term and solid plans to stimulate the interests of students in reading English 
literature originals (ELOs) further. For example, teachers introduce originals which are suitable for their reading whether in contents or in difficult levels. In fact, students who really are favor of reading English literature originals (ELOs) don't easily give up reading when meeting challenges such as problems in words or in structures, they will "Resort to dictionary right after when meet unknown word", which makes up to $38.9 \%$; or "Resort to dictionary later when finished reading, which is $15 \%$; and $14.2 \%$ will "Use directly internet translators"; also 17.7\% "Read Chinese edition at the same time (ex. book in both ChineseEnglish)"; still 4.4\% students express they will "Ask someone for help". From above, it is not hard to find a large percentage of students actually like making an attempt to touch the originals even they have met challenges and difficulties.

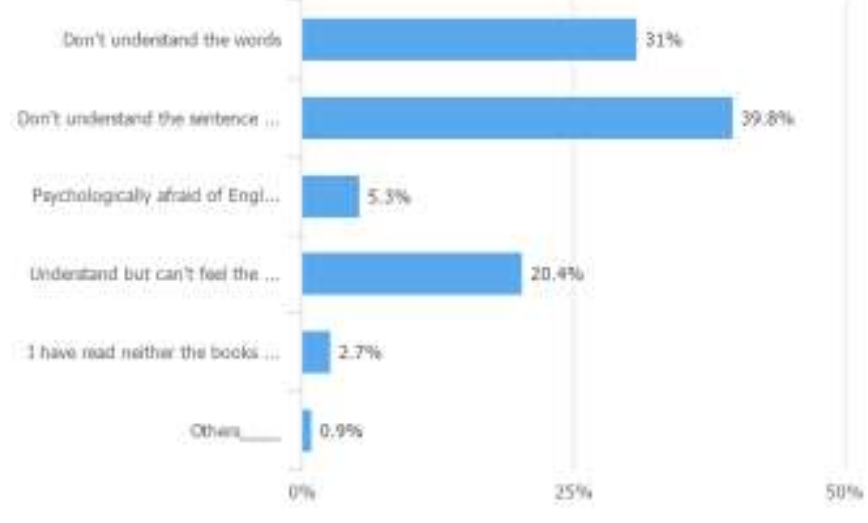

Fig. 6. What problems have you encountered most often when reading them?

\section{E. The Question Among the English Literature Originals, which Kind of Books Have You Read the Most}

Compared with History, Horror and Biography, categories such as Romance, Adventure, Fantasy or Science fiction are students' preferences. Gladly, the Treasury of English literature is never short of these kinds of works. It is recommended that teachers should introduce some works which meet the needs of reading originals at or out of class. Certainly, the degree of difficulty should depend on the levels of students' English, but one thing is sure, once being attracted in reading, students would be captured by the fantastic, terrific plot deeply, and unconsciously their English reading would be improved step by step. Ideally, they will have another in their hands soon.

\section{F. The Question What do you Think of English Literature Originals that You Have Read}

With courage, passion and eagerness, students have made great attempt to touch and read the so-called big works "English Literature Originals" with difficulties and challenges. "Fig. 7" shows that, gladly, after reading one or two English literature originals at least $23.9 \%$ students consider that reading originals was "Mostly OK and not afraid to read a new one". It illustrates clearly that not few students have a strong foundation of English, and they will not refuse the recommendation from schoolfellows and teachers, most properly if an original is good enough or bestselling, the original would be circulated widely among these students. But it couldn't be denied either that majority of students still think originals' reading not easy, especially after they have finished reading and have had their own reading experiences. $36.3 \%$ of them mention they have finished with lot of aids, now they don't know if they have the courage to read another one; and the same percent of students admitted originals' reading very difficult and wanted to give up several times during reading.

To deal with this situation, it's strongly suggested that students should evaluate the Difficulty Index while choosing their original works. The Difficulty Index could be sensed or judged by the originals' content, length, vocabulary, style, and other factors. Usually, contemporary originals are easier than the works of the age, because these works mainly describe the current society or the current trends, which have no or little gaps among students' cognition worldwide.

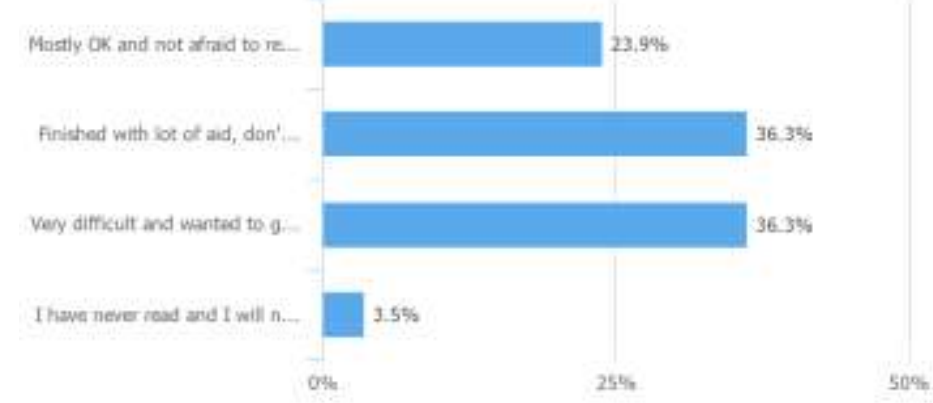

Fig. 7. What do you think of English literature originals that you have read? 
Further, teachers should make positive directions about some works towards students before and after reading. And if time possible, discussing about the original that one has read would be the encouraging method between students or students and teachers. Finally, watching films adapted from the original also is a productive way to help us comprehending the originals deeply, which makes us reading interesting and comprehensible. Films adapted from the originals such as Pride and Prejudice, Lawrence of Arabia, Madame Bovary help students to learn the literature masterpieces from another perspective, vividly in detailed picture descriptions.

\section{G. The Question What do You Think of English Literature Originals in General}

Beyond our expectation, most students like reading English literature originals out of their hearts and take original reading into serious consideration. According to Fig. 8 below, up to $63.7 \%$ of students all agree that English literature original reading is effective way to learn English; and $46.9 \%$ students say English literature original reading can be interesting; similarly, a considerable proportion of $47 \%$ students also express their wishes, that is "I prefer to watch movies or series adapted from the books". As following figure. 8 at the bottom of the page, only $14.2 \%$ consider English literature originals are useless to learn English.

The questionnaire has shown the optimistic perspective about students towards English literature originals. If the fears, the confusions, the difficulties could be overcome and peeled off reasonably, it's believed that students would have more passion for and confidence about English literature originals' touching.

\section{REFLECTIONS ON INVESTIGATIONS}

Reading of English original works is an important way for students to understand western culture, improve English language ability and literary quality, develop noble sentiment and aesthetic taste, cultivate English language sense and thinking. So in reading the classic works as Walden and other writings, we can sense the charm and beauty of the language and Henry David Thoreau peculiar style of writing.

The famous comments on Solute from Walden and other writings by Henry David Thoreau, American distinguished poet, philosopher, have affected generations worldwide deeply, the beautiful language and profound philosophy can be easily sensed and make people unforgettable.
Fig. 8. What do you think of English literature originals in general?

"I find it wholesome to be alone the greater part of the time. To be in company, even with the best, is soon wearisome and dissipating. I love to be alone. I never found the companion that was so companionable as solitude. We are for the most part more lonely when we go abroad among men than when we stay in our chambers. A man thinking or working is always alone, let him be where he will. Solitude is not measured by the miles of space that intervene between a man and his fellows. The really diligent student in one of the crowded hives of Cambridge College is as solitary as a dervish in the desert." [1]

By reading this, it is not hard for students to get the essence of language, to taste the charm of the language of great works from the English originals. Unconsciously they would have developed a strong love for English literature original reading.

It is not difficult to find English as the world lingua franca would still play the dominant part in the world activities for a long time. The core of English ----- the culture, the customs, the lifestyle, the behaviors, the thought, attitudes of native speakers towards things is all contained in the English literature originals. Ignorance of English literature originals, no one could say he has mastered English well. So to improve the study of English literature originals, both teachers and students should attach great importance to it subjectively as well as objectively.

Subjectively, deliberately set aside time every week to read, to watch or to discuss the works which are comparable to students' levels. Attempt to keep the habit well and develop the interests in English literature originals.

Objectively, teachers will stress the importance of English literature originals by introducing some at class from time to time, or even incorporate the original teaching into the teaching programs, and then make an investigation into the students' original study. The content and the time of college English class also should be suggested to be flexible and increased appropriately. At the same time, due to the limited teaching time, after-class assignments would be better supplementary to the class, for example, some chapters of original books could be assigned to students to read, 
discuss. Certainly a written report after reading also could be required in study group per week. All these measures could effectively strengthen students' study of English literature originals.

By these effective ways, the touch of English literature originals would be greatly increased, students can gradually have a deep insight into the treasury of great works and understand them, like them, get knowledge from them. Once students really take English literature originals as the essential part of their study and life, English progress is unstoppable. Only can students realize the positive effects of English literature originals, they can be pushed to move forward to their desired destination.

\section{CONCLUSION}

David Crystal, a well-known British linguist has pointed out in his book English as a Global language "The English language has already grown to be independent of any form of social control...it proves impossible for any single group or alliance to stop its growth, or even influence its future."[2] And the book The Cambridge Encyclopedia of English "No one can know for sure what the future of English will be like. Because no language has ever been the same as English at present. But all indications are that, unlike any previous language, the use and spread of English is as fast as rolling down a mountain, and attracts new non-native speakers of English."[3]

In order to acquire strong English language application and communication skills, and integrate Chinese and western culture, it is imperative to read English original works.

"In one way an arrow moves, in another way the mind. The mind indeed, both when it exercises caution and when it is employed about inquiry, moves straight onward not the less, and to its objet."[4] Armed with English literature originals, students are expected to go straight onward to its object.

\section{REFERENCES}

[1] Henry David Thoreau, Walden and other writings, Boston and New York Houghton Mifflin company, The Riverside Press: Cambridge, 1906, pp. 150.

[2] David Crystal, English as a global language, Cambridge University Press, 2003, pp. 190.

[3] David Crystal, The Cambridge Encyclopedia of English, Cambridge University Press, 1995, pp. 423.

[4] Aurelius, Marcus. 2008. Meditations, Central Compilation \& Translation Press, pp. 349.

[5] Huang Yanping, "Reading a Large Number of English Originals is an Important Means to Improve the Ability of Vocational College Students to Communicate in English. in press.

[6] Wang Jingfang, "On Learning Strategies in English Original Reading," New West, 14 issues, pp. 147-148, in press. Stephen D.Krashen, Principles and Practice in Second Language Acquisition, Pergamon Press Inc, 1982, pp. 125-146.

[7] Guo Junye, "A survey of college English reading disabilities and their teaching countermeasures-Taking the 3 classes of the 05 English education major at the beginning of the Zhengzhou Teachers' College as an example, Zhengzhou Normal University, pp. 96,137, in press. 